\title{
ARQUITETURA ESCOLAR E O ENSINO DE EDUCAÇÃO FÍSICA: RELAÇÕES (IM)POSSÍVEIS
}

\section{Camila Fagundes de Oliveira}

Universidade Federal do Rio Grande do Sul, Porto Alegre, Rio Grande do Sul, Brasil

\section{Lisandra Oliveira e Silva}

Universidade Federal do Rio Grande do Sul, Porto Alegre, Rio Grande do Sul, Brasil

\section{Vicente Molina Neto}

Universidade Federal do Rio Grande do Sul, Porto Alegre, Rio Grande do Sul, Brasil

Resumo: Este estudo teve por objetivo compreender como os espaços físicos da escola são apropriados pelos professores de Educação Física (EF) nas aulas de $5^{\mathrm{a}}$ à $8^{\mathrm{a}}$ séries do Ensino Fundamental. A pesquisa foi realizada em uma escola da Rede Estadual de Ensino de Porto Alegre/RS com 4 professores de EF. Trata-se de uma etnografia educativa e os principais instrumentos utilizados foram: observação participante, diário de campo, entrevista e análise documental. Percebemos que os professores de EF associam muitas das limitações do seu trabalho pedagógico a (in)existência de espaços e materiais referentes a essa área de conhecimento. Além disso, observamos importantes relações entre: as organizações e as apropriações desses locais/equipamentos pelos professores com a prática pedagógica em EF.

Palavras-chave: Espaço Físico. Prática Pedagógica. Educação Física.

\section{Introdução}

O presente artigo objetiva compreender como os professores de Educação Física (EF) se apropriam do espaço físico escolar, a partir das representações que possuem dos locais que utilizam nas aulas de $5^{\text {a }}$ à $8^{\mathrm{a}}$ séries do Ensino Fundamental, enfatizando as interferências que esses professores atribuem a dimensão material e arquitetônica da escola na construção e no desenvolvimento das suas práticas pedagógicas.

Compreendemos espaço físico como uma forma de representação social, ou seja, como organização social que é construída pelos diversos sujeitos sociais através do tempo, portanto, histórica, e, por isso, interligada a produção de cultura, de sujeitos e de sociedade. Estudar a dimensão material e de instalações da escola no contexto desse estudo se justifica, pois, esta é entendida como um espaço peculiar e de dupla dimensão em que um conjunto de regras e padrões tratam de homogeneizar e (de)limitar as ações dos sujeitos. Há uma constante apropriação dos espaços, das normas, das práticas e dos saberes que dão forma a vida escolar.

O tema deste estudo concentra-se na prática pedagógica dos professores de $\mathrm{EF}$, em uma escola Estadual da cidade de Porto Alegre, enfatizando o espaço físico e as suas representações. Desse modo, para pensar a relação do professor com a arquitetura escolar propusemos a seguinte questão central que orientou esse estudo: Como os professores de EF se apropriam do espaço físico da escola e de que maneira ele (de)limita a sua prática pedagógica?

Este artigo está dividido em quatro seções. Em seguida trataremos de apresentar as considerações metodológicas da pesquisa. Posteriormente abordaremos as categorias de 
análise da investigação: "Espaços Pedagógicos" e "Autonomia docente". Por fim, apresentamos algumas conclusões e as principais aprendizagens que tivemos na realização dessa investigação.

\section{Considerações metodológicas}

Esta pesquisa trata-se de uma etnografia educativa. Assim sendo, os instrumentos que foram selecionados para a coleta de informações, são os que na pesquisa qualitativa, possuem certo grau de flexibilidade na formulação das questões de pesquisa, e, desse modo, buscam descrever, explicar, interpretar as representações e os significados que um grupo específico atribui as suas ações e vivências diárias: a observação participante, a entrevista semiestruturada, o diário de campo e a análise de documentos (TRIVIÑOS, 2001; MOLINA NETO, 1999; MINAYO, 1994).

A escolha pela etnografia se deve ao fato de entendermos que esse método possibilita uma relação interativa e cúmplice entre os sujeitos envolvidos no processo de investigação. É uma forma de fazer pesquisa muito utilizada no campo da Educação, principalmente em estudos que se dispõem a compreender os fenômenos complexos e subjetivos como os que acontecem no âmbito da escola. Algumas características que definem esse método de pesquisa são: a) o pesquisador é o instrumento principal na coleta e na análise dos dados; b) a preocupação com o significado na perspectiva dos sujeitos investigados; c) uma descrição profunda das situações, pessoas, ambientes, depoimentos e diálogos (NEGRINE, 1999; ANDRÉ, 1998).

As observações das aulas dos professores de Educação Física foram assistidas em diversos locais da escola, como por exemplo: nas quadras, nos estacionamentos ${ }^{1}$, no saguão ${ }^{2}$, nas salas de aulas das turmas, na sala de Educação Física e na rua. Procuramos descrever e anotar fielmente, em diário de campo (um caderno), as práticas e as falas dos professores procurando não emitir qualquer juízo de valor. As observações foram realizadas em um período de sete meses. Observamos 35 aulas de Educação Física, o que totalizou aproximadamente 100 horas de observação.

Foram analisados os Planos de Trabalhos dos professores e o Projeto Político Pedagógico da escola investigada. Também foram realizadas quatro entrevistas de forma particular, sendo uma com cada colaborador.

Dessa maneira, o processo metodológico realizado neste estudo foi o de observar um contexto particular, neste caso, o cotidiano de quatro professores de EF de uma Escola Estadual de Porto Alegre/RS, registrar as informações em diário de campo, ouvir os docentes através das entrevistas, analisar os documentos dessa instituição, confrontando essas informações com os referenciais teóricos para, a partir disso, compreender a relação entre a apropriação do espaço físico escolar e a prática pedagógica do professorado de EF nas aulas de $5^{\mathrm{a}}$ a $8^{\mathrm{a}}$ séries do Ensino Fundamental.

A seguir apresentamos algumas reflexões a partir das categorias construídas ao longo do processo de pesquisa.

\section{Espaços pedagógicos: da formação do professor ao ensino de educação física no contexto da arquitetura escolar}

De acordo com Molina Neto (1997) compreender a formação dos professores

\footnotetext{
${ }^{1}$ Espaço irregular de concreto e descoberto localizado no pátio da escola.

${ }^{2}$ Ambiente coberto também utilizado para as aulas de Educação Física em dias de chuva.
} 
significa entendê-la a partir da perspectiva da cultura docente, que consiste olhar além das particularidades do currículo de Formação Inicial e dos programas de Formação Permanente, outros elementos, tais como: a experiência vivida pelos professores, sua prática cotidiana nas escolas, o conhecimento elaborado nessa experiência e nesta prática, o processo de formação e as crenças que desenvolvem.

A Formação Inicial em Educação Física, de acordo com Molina Neto (1997), possui certas ausências e necessita uma revisão crítica no que se refere ao trabalho do professor na escola. Isso se deve ao fato do currículo das instituições formadoras oferecerem poucas alternativas para um trabalho mais consistente no âmbito escolar. Dessa forma, o professor não vem sendo bem preparado para trabalhar em escolas públicas, e sim, sendo qualificado para trabalhar em outros ambientes de trabalho em consequência dos modismos, da especialização do trabalho e das mudanças das formas de vida das comunidades urbanas.

Ao lado disso, Resende (1994) explica que a criação e a descoberta de outros espaços de prática docente em EF, tais como parques, praias, clubes, academias, hotéis, condomínios, dentre outros, que viabilizam a prática das atividades corporais, além de se mostrarem alternativos, parece, nesse sentido, estar contribuindo para as manifestações da "descolarização" da EF. O próprio espaço físico escolar, não dá conta do universo de possibilidades existentes para a prática das atividades corporais (quer pelo imaginário da hierarquização social, quer pelos tipos de possibilidades que eles oferecem, dentre outros aspectos).

Sendo assim, Molina Neto (1997) ressalta que o despreparo dos professores para trabalhar na escola pública, além de se caracterizar pelas diferentes condições materiais objetivas entre o "como aprendem" e o "como vão ensinar", também está na seleção do conhecimento, e na dependência do material e do espaço físico que se oportuniza ao estudante do curso de Formação Inicial em EF.

Morais (2004) argumenta que o discurso teórico acadêmico que chega à escola parece desmedido, sem efeito, pois esbarra na dita "experiência" do dia-a-dia que naturaliza a escola e seus desafios, negando, dessa forma, qualquer possibilidade de (re)significação das estruturas e do sentido da EF escolar. A questão do espaço físico e dos materiais, nesse contexto e ao nosso olhar, não é, portanto, a do espaço em si (sua existência ou não), mas da concepção norteadora dessa prática e da forma como vem sendo tratada/trabalhada nos cursos de formação docente.

O processo de formação: O que pensam os professores?

O currículo do curso de Formação Inicial é percebido pelos professores como um fator limitante no seu processo formativo, especialmente no que tange ao trabalho que realizam na escola. A justificativa é a de que este currículo parece ter sido idealizado, ausente de articulação mais significativa entre os conhecimentos específicos e os conteúdos relacionados a metodologia, além de pouca discussão sobre a dimensão simbólica dos espaços e da prática pedagógica reflexiva. $\mathrm{O}$ que pensa a maioria dos professores é que se "aprende na faculdade que se tem muitos outros esportes, muitas outras atividades, mas não se tem muita alternativa, não se tem bola, tabelas, tudo é muito difícil, nunca é o ideal". Dessa forma, o saber universitário é visto pelos docentes como "insuficiente", enquanto que a prática que desenvolvem parece ser a fonte de solução para os problemas que a Formação Inicial não contempla, bem como a busca por cursos de Pós-Graduação. Os professores percebem nesses espaços de Formação Permanente uma forma de ascender socialmente em face ao incentivo que as administrações públicas dão a esse tipo de atividade.

No âmbito do contexto escolar, os docentes sentem-se "aprisionados" e "limitados"

Pensar a Prática, Goiânia, v. 14, n. 2, p. 1-10, maio/ago. 2011 
para exercer sua prática pedagógica pela falta de condições materiais e físicas (espaços e equipamentos) que dispõe a escola em que trabalham e presumem essa situação a lacuna existente entre a Formação Inicial e a experiência que construíram ao longo da profissão. Decepcionados, deixam uma questão para reflexão: "Eu tenho um espaço, eu tenho algumas bolas, o que se vai inventar?"

Arquitetura escolar: entre limites e possibilidades

O espaço da escola não é apenas um lugar que integra alunos, livros, professores, mas um ambiente em que se realizam atividades de aprendizagens. Ele próprio é educativo e contém "conteúdos". A escola, portanto, é mais do que uma estrutura física/material, é produção de aprendizagens que envolvem relações sociais de formação de pessoas. É possível pensar que há uma docência do espaço.

O trabalho do professor de EF se depara, segundo Bracht et al (2003), com a necessidade de melhor equipar as escolas com materiais referentes às aulas, bem como destinar especial atenção à manutenção das instalações adequadas e necessárias para as aulas de EF.

Os espaços físicos da escola investigada são vistos pelos professores como espaços "bons de trabalho". Os argumentos que conferem tal declaração são: a escola ser de grande porte e por possuir três quadras poliesportivas, além de outros espaços alternativos, como um "areião" (espaço aberto, sem demarcação e preenchido com areia), o "piso do estacionamento" (espaço irregular de concreto e descoberto), dois "saguões" (ambiente coberto também utilizado como espaço de convivência em dias de chuva) e uma sala específica para a disciplina de EF. Quanto aos materiais, os docentes são unânimes ao qualificarem esses recursos como "muito pobres", "insuficientes" e "sucateados" pelo tempo de uso. É interessante destacar que os espaços físicos e os materiais citados pelos docentes foram aqueles que eles mais utilizam na suas aulas, ou seja, as quadras e as bolas, como observamos na realização do trabalho de campo dessa pesquisa.

O espaço físico é considerado por Dayrell (1996) uma construção social que é produzida pelos sujeitos sociais. A escola, nesse contexto, também é entendida como tal, sendo assim, "organiza, separa e hierarquiza" seu espaço, a fim de diferenciar trabalhos, logo, as relações sociais que estão envolvidas no seu entorno.

Formalmente há um local pré-determinado para cada nível de ensino ocupar nesta escola, ou seja, para cada professor que trabalha com essas turmas se apropriar. Todavia, em alguns momentos os professores "quebram" com as regras de hierarquia que norteiam a apropriação dos espaços da escola e, dessa forma, procuram construir outras formas de organização, através de "combinações" e de "acordos" que criam entre si.

Os docentes percebem a demarcação/tabelação dos lugares que podem ocupar como um fator negativo, pois sentem-se restringidos em realizar seu trabalho. Dessa forma, os educadores utilizam como estratégia a ampliação dos espaços da escola para além de seus muros. É possível pensar que os professores sentam-se "sufocados" no espaço escolar, não só pelo fato dos ambientes serem controlados, divididos, reduzidos entre os professores, mas também por estes locais não conterem outros significados e possibilidades que vislumbram. Assim, os docentes procuram buscar alternativas em lugares extra-escolares, como por exemplo, a rua, como uma forma de romper rotinas e desenvolver outras atividades que o mundo da escola parece não dar conta.

Compartilhamos do entendimento de que se o espaço da escola expressa uma determinada concepção educativa, os recursos materiais que esta dispõe também manifestam tal característica. Os equipamentos que tem prioridade para os docentes são os esportivos,

Pensar a Prática, Goiânia, v. 14, n. 2, p. 1-10, maio/ago. 2011 
visto a ênfase dada, especificamente, às bolas. Nesse sentido, foi possível perceber que as bolas, bem como as quadras têm seus usos específicos na escola investigada, ou seja, refletem a associação entre o ambiente e a sua função, ação à qual elas foram originalmente concebidas/construídas. Representam no sentido "usual" ou "especializado" o esporte coletivo, os tradicionais, tratados pelos professores de EF desta escola, tais como: o vôlei, o futebol, o handebol e o basquete; os demais materiais como colchonetes, bastões remetem a ginástica, conteúdo que parece que tem perdido a importância nas aulas de $\mathrm{EF}$, já que, durante o período que estivemos realizando a observação, esta manifestação corporal ficou restrita a parte de alongamento realizada em algumas aulas dos professores colaboradores.

Destacamos, ainda, que a arquitetura e a ocupação do espaço físico não são neutras. De acordo com Dayrell (1996) desde a forma de construção até a localização dos espaços, tudo é delimitado formalmente de acordo com princípios pré-estabelecidos, que enunciam uma expectativa de comportamento das pessoas que usufruem desses locais. Neste sentido, a arquitetura escolar interfere na forma de circulação dos indivíduos, e na definição das funções para cada ambiente.

A quadra é o espaço mais utilizado pelos professores no desenvolvimento de seu trabalho na escola investigada. Uma das maneiras que desfrutam deste local é para realização de jogos de modalidades esportivas com os alunos. No entanto, percebemos que os educadores, em alguns momentos, não conseguem realizar essas atividades com toda a turma num mesmo local, e, dessa forma, utilizam o espaço dos estacionamentos para entreter/manter os alunos que estão "de fora" envolvidos em alguma atividade.

O estacionamento, neste contexto de aula, é um ambiente que não representa a realização de um conteúdo tradicional da EF, mas acaba sendo apropriado pelos professores dessa área para realizar seu trabalho. Este espaço é pensado pelos professores como um lugar livre, pois é apropriado de diversas formas e serve de local em que tudo acontece, isto é, espaço de atividades construídas pelos alunos, de realização de atividades alheias a aula como: conversas, brincadeiras, realização de tarefas de outras disciplinas, dentre outras.

Os recursos materiais (bolas, arcos, cones, cordas, dentre outros) utilizados neste tipo de aula, são oferecidos em grandes quantidades para os alunos e parece ser uma estratégia utilizada pelos professores no sentido de expandir o espectro de atividades que atinjam o interesse e o envolvimento do maior número de alunos na aula. Dessa forma, os espaços físicos como o estacionamento, o areião e o saguão, se tornam espaços "coringas" de maneira a manter os alunos engajados em alguma atividade de acordo com seus desejos.

A sala de aula é pouco apropriada pelos professores de EF nas suas aulas. Este local é utilizado como opção em dias de chuvas ou quando os professores têm necessidade de "passar um conteúdo", como eles denominam, para os alunos. Desta forma, Bracht et al (2003) afirma que quando o professor adjetiva a quadra como espaço de "aulas práticas" e a sala de aula como local de "aulas teóricas", quando se percebe que os locais destinados às aulas de EF apresentam-se conformados de acordo com as modalidades esportivas, encontramos significados importantes que anunciam o tipo de prática realizada, condicionando, de alguma forma, as suas possibilidades.

A quadra ou os demais espaços abertos da escola parecem que não são vistos pelos professores com as mesmas possibilidades da sala, já que na troca de cenários, "sala de aula" para "pátio", foi possível perceber a perda de rigor, por parte dos professores, com a conduta dos alunos e com o envolvimento deles na aula. $\mathrm{O}$ espaço aberto parece ser compreendido pelos professores como local de liberdade, de licenciosidade, de descompromisso com a prática, isto é, livre da rigidez que a sala de aula lhes impõe.

Pensar a Prática, Goiânia, v. 14, n. 2, p. 1-10, maio/ago. 2011 


\section{A autonomia docente nas relações entre os professores de educação física, o espaço e a comunidade escolar}

Pensamos que é através do planejamento coletivo que os professores estabelecem suas práticas docentes, decidem os objetivos da sua disciplina (gerais e específicos), os saberes, os conteúdos, a metodologia de ensino, a forma de avaliação e os recursos materiais que necessitarão para realização das aulas ao longo do ano letivo.

No Plano Anual dos professores de EF, constam os recursos que destacam como necessários para o desenvolvimento dos conteúdos que pretender trabalhar durante o ano letivo, tais como bolas de voleibol, de handebol, de basquetebol, de futsal, de tênis, além de outros como: cordas, bastões, saquinhos de areia, colchonetes, bolinhas de meia, vídeos, filmes, cd's, jalecos, cones, redes de voleibol. Embora os docentes apontem diversos recursos como necessários para o pleno desenvolvimento do seu trabalho, apenas alguns destes foram utilizados pelos professores durante o período em que estivemos realizando as observações, isto é, as bolas, as cordas, os jalecos e a rede de voleibol.

De acordo com Bracht et al (2003) conhecer os esportes não significa mais apenas saber executá-los, mas também saber suas regras, sua história, sua inserção sócio-política. No Plano de Trabalho dos professores de EF, colaboradores da pesquisa, há um espaço destinado para os objetivos que traçam para disciplina. A proposta de EF escolar, no contexto investigado, está profundamente vinculada com a aptidão física, haja vista a finalidade que os educadores asseguram para essa disicplina. Citamos alguns exemplos: "desenvolver no aluno a área motora, condições físicas e orgânicas; desenvolver agilidade, flexibilidade, destreza, capacidades, habilidades para uma vida saudável" (PLANO DE TRABALHO, 2008).

Percebemos que os jogos "pré-desportivos", "esportivos", "modalidades esportivas", são os que guiam as práticas pedagógicas do professorado de EF da escola investigada. Outros conteúdos, do mesmo modo, são citados pelos docentes, entretanto, com menor ênfase, pois se limitam ao encerramento da aula: as atividades lúdicas e as brincadeiras. Sendo assim, os esportes são os principais e os mais valorizados conteúdos trabalhados nesta escola. Fato que também foi identificado por Oliveira (2006) nos seus estudos realizados nesta instituição sobre as teorias pedagógicas da EF.

Os demais conteúdos da EF acerca das culturas corporais que, segundo Soares (1996), se afirmaram como linguagens através do tempo e que deveriam ser tratados pela escola, como recomendam os Parâmetros Curriculares Nacionais, tais como: os jogos, a dança,as lutas, a ginástica, não estão contemplados nos Planos de Trabalho dos professores colaboradores ou são tratados de forma secundária, o que nos leva a pensar que estes conteúdos não esportivos podem ser pensados como conteúdos menores, ou que não tenham vínculo com os objetivos dos professores. $\mathrm{Ou}$, ainda, porque a escola pode não oferecer os espaços e os materiais específicos e adequados para o desenvolvimento dessas práticas, o que, por conseguinte, sugere (in)visibilidade e menor importância à estes conhecimentos.

Os professores de EF acreditam que a (in)existência de espaços e materiais específicos de determinados conteúdos da área (de)limitam o seu trabalho na escola. Os docentes enfatizam que com mais recursos poderiam trabalhar outros conteúdos da disciplina como o atletismo e o futebol de campo, todos dentro do fenômeno esportivo. De acordo com Santos (1997), não só os instrumentos de trabalho exercem domínio sobre os sujeitos, mas o resultado condensado do seu trabalho impõe-lhes uma prática que define o seu modo de agir.

A forma como os professores organizam as aulas explicitam algumas concepções que possuem sobre a EF escolar. O coletivo docente pesquisado segue uma estrutura organizada de aula em que os conteúdos que planejam ensinar têm seu momento próprio, isto é, parte inicial, principal e final. Assim, os docentes iniciam a aula com uma atividade de

Pensar a Prática, Goiânia, v. 14, n. 2, p. 1-10, maio/ago. 2011 
alongamento e aquecimento, posteriormente realizam uma atividade recreativa seguida de exercícios de fundamentos de uma determinada modalidade esportiva que estão ensinando no trimestre. Por fim, realizam jogos entre pequenos grupos de alunos e encerram a aula com uma atividade de volta à calma.

Destacamos que esta forma de organizar os conteúdos está conectada a um modelo pré-determinado de EF que evidencia o caráter da "esportivização" e da "aptidão física" que está contida nessa prática, isto é, mesmo que os professores não percebam os fundamentos teóricos e o caráter interessado da organização da aula que realizam, há significados importantes que os guiam nessa direção (BRACHT et al, 2003).

Durante o período que estivemos em campo, observando os professores de EF na escola investigada, pudemos perceber que os trabalhos que desenvolvem é mediado por meio de constantes relações que estabelecem entre os sujeitos que compõe esse universo. Assim sendo, as práticas dos docentes são (re)construídas a partir dos vínculos de amizade, cumplicidade, desconfortos, resistências, estranhamento, isolamento, descompromissos, agressões, que firmam permanentemente com os professores, alunos, funcionários, pais, dentre outros.

Outra relação específica do contexto da escola é a que ocorre entre os sujeitos e a estrutura física em questão. Essa ligação é (re)significada a todo o momento pelos seus integrantes e tem sentidos diversos para aqueles que estão envolvidos neste espaço.

A respeito do vínculo entre professores de EF com a comunidade escolar, Molina Neto (1998) observa que mesmo que essa relação seja cordial, é um relacionamento formal, consequência das características dessa área de conhecimento, sobretudo pelo lugar onde se desenvolve a sua prática - dividem um ambiente indefinido, pouco frequentado pelos demais professores, em que as atividades desenvolvidas pelos alunos em aula são diferentes da maioria das atividades "tradicionalmente" escolares.

A partir da voz dos educadores observamos que existe pouca "união" entre o professorado de EF na escola em questão, embora procurem ter um "bom relacionamento entre si". Os professores justificam a falta de integração à diferença de horários e turnos que frequentam a escola. Dessa forma, o tempo escolar parece não favorecer a troca, o diálogo e o encontro entre os pares.

Foi possível perceber que os jogos escolares agregam, de alguma forma, os docentes de EF, embora a realização destes gere conflitos referentes aos conhecimentos e aos objetivos que cada um percebe para a àrea. Outro dilema que gera desarmonia e provoca discordância entre o coletivo da EF nesta escola são as posturas e os privilégios dados pela direção a certos professores quanto a utilização dos materiais e também da estrutura física. Os equipamentos e os ambientes escolares, neste caso, se tornam elementos de disputa de poder e de privilégios.

Os professores argumentam ter um relacionamento agradável com os alunos nas aulas de EF, resultante dos laços de amizade e de respeito que estabelecem, o que segundo os próprios docentes auxilia no andamento das aulas. Essa cumplicidade entre o professor de EF e o alunado, segundo Molina Neto (1998) aumenta ao longo da relação de ensinoaprendizagem e com a comunicação que constroem através da linguagem oral e corporal. Observamos que há outros fatores vinculados a esse processo, como por exemplo: a falta de autoridade do professor, a falta de rigor com a sua prática, a licenciosidade em favor da resistência, o descompromisso com a sua prática em favor dos desejos dos alunos. Para Resende (1994) é necessário superar a crença de que o critério de excelência de uma aula de EF escolar seja fornecido pelo tempo despendido com as atividades práticas, pela alegria exteriorizada pelos alunos e pelo nível de harmonia e aceitação por parte deles. Uma aula implica em conflitos inerentes a qualquer forma de interação social.

No intuito de conseguir essa aula estigmatizada como "ideal”, ou seja, com atividades

Pensar a Prática, Goiânia, v. 14, n. 2, p. 1-10, maio/ago. 2011 
interessantes, com alunos motivados, os professores terminam curvando-se aos anseios dos educandos perdendo, dessa forma, a autoria pedagógica que caracteriza a profissão docente. Resende (1994) lembra que a postura do professor, apesar de ser afetiva nas relações com os alunos, deve ser diretiva, pois ele é o único responsável pela mediação dos conflitos escolares e sociais, criando um ambiente de reflexões e decisões superadoras das situações-problemas que surgem durante a sua prática pedagógica.

Nesta perspectiva de aula, os espaços físicos da escola, e em especial os específicos da EF, são delegados pelos professores aos educandos, quando aqueles sentem o desinteresse destes com a proposta da aula. Os alunos, então, passam a ser os responsáveis pelas escolhas das práticas e, por conseguinte, dos locais e materiais da escola. Nesse sentido, os docentes assumem a tarefa de "cuidadores". Os espaços, nestas circunstâncias, se transformam em locais de permanentes apropriações de alunos, e a aula, em um momento de constante movimentação e circulação de estudantes pelos diversos ambientes que configuram a arquitetura escolar.

\section{Conclusão}

Foi possível compreender que os professores de EF sentem dificuldades de desenvolver determinados conteúdos da cultura corporal na escola, tais como, dança, lutas, ginástica, por conta da inexistência de locais e de materiais específicos referentes a essas práticas. Dessa forma, os docentes limitam-se aos conteúdos esportivos, dado aos equipamentos que a escola oferece para essa temática.

Além disso, observamos que a própria quantidade de materiais disponibilizados pela escola reflete na forma como os docentes estruturam as suas aulas. Os dias de chuva parecem ser os dias que mais interferem no trabalho e na apropriação dos espaços escolares pelo professor de EF. A organização hierárquica dos ambientes da escola, organizada pelos próprios educadores, também é um fator que (de)limita o trabalho dos professores de EF, assim como as relações que os mesmos estabelecem com a comunidade escolar.

Para finalizar, destamos que foi possível observar que os professores de EF, colaboradores da pesquisa, têm dificuldades de (re)significar os espaços escolares e os materiais que a escola oferece. Ressaltamos que seja preciso e necessário pensar em espaços no seu sentido "múltiplo", ou seja, que possam refletir a flexibilização da utilização dos ambientes, de modo que mediante os arranjos necessários, eles possam abrigar ações diferentes daquelas para as quais eles foram originalmente construídos. Embora consideremos que seja de suma importância que as escolas possuam espaços específicos para a EF, assim como materiais adequados, parece-nos, ao mesmo tempo, ser importante discutirmos a respeito da dimensão simbólica dos espaços escolares e da representação que estes têm para os professores que trabalham com essa disciplina nesse contexto.

\section{Referências}

ANDRÉ, M. E.. A etnografia da Prática Escolar. Campinas: Papirus, 1998.

BRACHT, V. et al. Pesquisa em ação: a educação física na escola. Ijuí, RS: Editora Unijuí, 2003.

DAYRELL, J.. A escola como espaço sócio-cultural. In: DAYRELL, J. (Org.). Múltiplos Olhares sobre educação e cultura. Belo Horizonte, MG: Editora da UFMG, v. 2000, p. 136$161,1996$. 
MINAYO, M. C.. Ciência, técnica e arte: o desafio da pesquisa social. In: MINAYO, M. C. (Org.). Pesquisa social: teoria método e criatividade. Petrópolis, Rj: Vozes, 1994.

MOLINA NETO, V.. Etnografia: uma opção metodológica para alguns problemas de investigação no âmbito da Educação Física. In: MOLINA NETO, V; TRIVIÑOS, A. N. (Orgs.). Pesquisa Qualitativa na Educação Física: alternativas metodológicas. Porto Alegre, RS: Editora da UFRGS/Sulina, 1999.

MOLINA NETO, V.. A prática dos professores de educação física das escolas públicas de Porto Alegre. Revista Movimento, v. 5, n. 9, p. 31-46, Porto Alegre/RS, 1998.

MOLINA NETO, V.. A formação profissional em Educação Física e esportes. Revista Brasileira de Ciências do Esporte, v. 19, n. 1, p. 34-41, 1997.

MORAIS, R.. Na prática docente a teoria se desmancha no ar: a resistência a teoria no espaço-escolar. Revista Educação, v. 29, n. 1, Santa Maria/RS, 2004.

NEGRINE, A.. Instrumentos de coleta de informações na pesquisa qualitativa. In: MOLINA NETO, V; TRIVIÑOS, A. N. (Orgs.). Pesquisa Qualitativa na Educação Física: alternativas metodológicas. Porto Alegre, RS: Editora da UFRGS/Sulina, 1999.

OLIVEIRA, A. B. A prática pedagógica dos professores de Educação Física do ensino fundamental da Rede Estadual de Ensino de Porto Alegre: um olhar a partir das Teorias pedagógicas. Porto Alegre, RS: Universidade Federal do Rio Grande do Sul. Monografia (Graduação em Educação Física Licenciatura), 2006.

PLANO DE TRABALHO DOS PROFESSORES DA ESCOLA ALAMEDA, 2008.

RESENDE, H. G.. Reflexões sobre algumas contradições da educação física no âmbito da escola e alguns caminhos pedagógicos na perspectiva da cultura corporal. Revista Movimento, v. 1, n. 1, p. 20-28, Porto Alegre/RS, 1994.

SANTOS, M.. Pensando o espaço do homem. São Paulo: Hucitec, 1997.

SOARES, C. L. Educação Física Escolar: Conhecimento e Especificidade. Revista Paulista de Educação Física, São Paulo, v. 2, p. 6-59, 1996.

TRIVIÑOS, A.. Bases Teórico-Metodológicas da pesquisa em Ciências Sociais. Porto Alegre: Faculdades Integradas Ritter, 2001.

\title{
SCHOLASTIC ARCHITECTURE AND THE TEACHING OF PHYSICAL EDUCATION: RELATIONS (IM)POSSIBLE
}

\begin{abstract}
This study aimed to understand how the physical spaces of the school are appropriate for teachers of Physical Education (EF) classes 5th to 8th grades of elementary school. The survey was conducted in a school in the State Schools of Porto Alegre/RS, 4 teachers of PE. This is an educational ethnography and the main instruments used were
\end{abstract}

Pensar a Prática, Goiânia, v. 14, n. 2, p. 1-10, maio/ago. 2011 
participant observation, field diary, interview and document analysis. We realize that teachers of PE associate many of the limitations of their work to teaching (in)existence of spaces and materials for this field. Furthermore, we observed significant relationships between: the organizations and the appropriation of local and/or equipment for teachers with pedagogical practice in EF.

Keywords: Physical Space. Pedagogical Practice. Physical Education.

\section{ARQUITECTURA DE LA ESCUELA Y LA ENSEÑANZA DE LA EDUCACIÓN FÍSICA: RELACIONES (IM)POSIBLES}

Resumen: Este estudio tuvo por objetivo comprender como los espacios físicos de la escuela son apropiados por los profesores de Educación Física (EF) en las clases de $5^{\mathrm{a}}$ a $8^{\mathrm{a}}$ series de la Enseñanza Básica. La investigación fue realizada en una escuela de la Red del Estado de Enseñanza de Porto Alegre /RS con 4 profesores de EF. Trata de una etnografía educativa y los instrumentos utilizados fueran: observación participante, diario del campo, entrevista y análisis documental. Percibimos que los profesores EF asocian muchas de las limitaciones de su trabajo pedagógico a (in)existencia de espacios y materiales referentes a esta área del conocimiento. Además, observamos importantes relaciones entre: las organizaciones y las apropiaciones de estos locales/equipamiento por los profesores con la práctica pedagógica en EF.

Palabras clave: Espacio Físico. Práctica Pedagógica. Educación Física.

Endereço para correspondência:

vicente.neto@ufrgs.br

Vicente Molina Neto

Universidade Federal do Rio Grande do Sul,

Programa de Pós Graduação Em Ciências do Movimento Humano

Rua Felizardo, 750

Jardim Botânico

90690-200 - Porto Alegre, RS - Brasil

Pensar a Prática, Goiânia, v. 14, n. 2, p. 1-10, maio/ago. 2011 